\title{
The security of medium truck with Engine brake (Jacobs) driving through the mountain highway long downhill slope
}

\author{
Wang Jianbo ${ }^{1,2, a}$, Chen $\mathrm{Bin}^{2, \mathrm{~b}}$, Wang Hengkai, ${ }^{3, \mathrm{c}}$, He Cao ${ }^{2}$ \\ ${ }^{1}$ School of Automobile, Chang'an University, P.O. Box: School of Automobile, Xi'an, Shanxi, \\ 710064 \\ ${ }^{2}$ Sichuan Vocational and Technical College of Communications, P.O. Box: Wenjiang District, Liu \\ Tai Road, No. 208 ,Chengdu, Sichuan, 611130 \\ ${ }^{3}$ China Faw Group Corporation R\&D Center, Changchun, Jilin, 130011 \\ a'Wjianbo2000@126.com, ${ }^{b}$ 52709460@qq.com, ${ }^{c}$ 452359762@qq.com
}

Keywords: straight truck, Jacobs engine brake,Mountain highway,continuous downhill,safety.

Abstract. In order to solve the problem that the truck should spray water to cool its brake during run the long downhill on mountain highway in winter, which can Lead to icy road and cause traffic accidents. We specially selected the straight truck $(6 \times 4)$ which install the engine brake (Jacobs), carrying carry out safety tests on Yaxi highway downhill sections in winter. The tests showed that $30 \%$ of vehicle overloading conditions, without the engine brake (Jacobs), relying on the service brake to control downhill speed, when the elevation drop of about $300 \mathrm{~m}$, the truck's highest brake drum temperature will rise to a hot recession critical failure temperature $\left(260{ }^{\circ} \mathrm{C}\right)$ above. If you continue driving, it will lead to break failure and loss of control. When the truck going downhill and open the engine brake (Jacobs), due to the brake load is greatly reduced, the brake drum temperature of the truck maintained at $150^{\circ} \mathrm{C}$ or less to maintain a good braking performance, and the truck can pass the $51 \mathrm{~km}$ gap between $1500 \mathrm{~m}$ long downhill safely. The results of field test shows that, when a straight truck going down a long downhill slope and open the engine braking (Jacobs), the brake maintain a safe speed without spraying water, and keeping good braking performance. So it can solve the straight truck pass the long downhill sections of mountain highway fundamentally and the brake is not tricking.

\section{Introduction}

The Chinese highway is built currently forward southwest mountain area depth propulsion, Due to natural conditions, the new highway with high elevation, steep slope, narrow roads and sharp curves, and has natural disasters constantly. Because the basis of vehicle operation safety conditions is poor, which have become accident-prone sections. Among of them, the Sichuan Yaxi highway has been opened to traffic, there are complex geologic conditions along the road, Form the North Niba mountain, south Niba mountain and north Tuowu mountain three long downhill slope, the slope length are $33 \mathrm{~km}$, $26 \mathrm{~km}$ and $51 \mathrm{~km}$, the average longitudinal slope are $2.28 \%, 2.57 \%$ and $2.97 \%$, ranked highest in China. Among the three long longitudinal sections, there are $22 \mathrm{~km}$ above the snow line, and some sections of a certain altitude is also affected by ice, snow, rain, fog and other inclement weather conditions, operational safety-shaped face a grim situation.

Therefore, The research team selected the Shanxi F2000(6×4)truck which assembly engine braking system (Jacobs), carrying the slope safety testing before the opening of Yaxi highway, so as to find solutions to the problem of how heavy trucks can pass the long downhill slope safely in the mountainous highway at winter Freezing season.

\section{The test conditions of road and vehicle}

The test vehicle configuration parameters

$$
\text { Tab. } 1
$$

The test vehicle configuration parameters

\begin{tabular}{|c|c|c|c|}
\hline Truck brand & Shanxi F2000 & Vehicle models & SX3255DR434C \\
\hline
\end{tabular}




\begin{tabular}{|c|c|c|c|}
\hline Engine Model & ISME345 30 & Engine power & 254KW/1900rpm \\
\hline Transmission & Fast 9JS180A & Drive form & $6 \times 4$ \\
\hline Curb weight tons & $13 \mathrm{~T}$ & Retarder & Jacobs \\
\hline Axle speed ratio & 5.262 & $\begin{array}{c}\text { Standard total } \\
\text { waich }\end{array}$ & $25 \mathrm{~T}$ \\
\hline
\end{tabular}

\section{Test equipment}

Vehicle performance detection system(Vbox 3), Infrared Temperature Measurement System, Anemometer, stopwatch, etc.

\section{Test road conditions}

(1) The north Niba mountain long downhill slope, $26 \mathrm{~km}$, average longitudinal slope $2.28 \%, 6.7 \mathrm{~km}$ above the snow line

(2) The north Tuowu mountain long downhill slope, $51 \mathrm{~km}$, average longitudinal slope $2.97 \%$, $16.7 \mathrm{~km}$ above the snow line.

(3) Ambient temperature $10^{\circ} \mathrm{C}$

\section{The engine brake (Jacobs) braking characteristics test}

The braking characteristics test carried on a straight road, the test truck gross weight of 32.5 tons (overload 30\%), for research engine brake(Jacobs) deceleration capacity to determine the characteristics of engine braking system.

\section{Test method}

(1)Transmission neutral taxi tests

Increase truck speed to $80 \mathrm{~km} / \mathrm{h}$, and then linked into the transmission in neutral gear, and slide freely, record the speed time-varying relational data in the test equipment.

Test in the opposite direction to do it again.

(2)Transmission with shelf taxi tests

Hanging into the five-speed transmission, and accelerating the truck to maximum speed, open the engine brake (Jacobs) switch, and slide freely, record the speed time-varying relational data in the test equipment.Test in the opposite direction to do it again.

Then turn the gearbox 6,7,8 file, test methods and the same five-speed taxi tests.

Measurement and calculation of the engine brake (Jacobs) brake force

Based on the above test methods, we can accurately detect the starting point of the vehicle running $\operatorname{speed}\left(v_{0}\right)$, the terminal velocity $\left(v_{t}\right)$, running time $(t)$, distance $(s)$, wind $\operatorname{speed}\left(v_{w}\right)$ and other parameters. According to the car driving equation shows:

$$
\delta_{\mathrm{i}} \cdot m \cdot \frac{d u}{d t}=F_{I}+F_{f}+F_{\mathrm{w}}
$$

In the equation:

$F_{7}$ :Jacobs braking force; $F_{f}:$ Wheel rolling resistance;

$F_{w}:$ Air resistance; $\quad m:$ Vehicle total quality; $\frac{d t u}{d t}:$ Deceleration;

$\bar{\delta}_{i}$ Rotating mass conversion factor for the corresponding stall;

$$
\begin{aligned}
& F_{j}=\delta_{\mathrm{i}} \cdot m \cdot \frac{d u}{d t}-\left(\mathrm{F}_{\mathrm{f}}+\mathrm{F}_{\mathrm{w}}\right) \\
& \frac{d u}{d t}=\frac{\left(\mathrm{v}_{0}-\mathrm{v}_{\mathrm{p}}\right)}{\tau} \\
& F_{j}=\delta_{\mathrm{i}} \cdot m \cdot \frac{\left(\mathrm{w}_{0}-\mathrm{v}_{t}\right)}{\tau}-\left(\mathrm{F}_{\mathrm{f}}+\mathrm{F}_{\mathrm{w}}\right)
\end{aligned}
$$


$F_{\mathrm{w}}=\frac{C_{D A U T}}{21.15}$

$F_{f}=\mathrm{G} \cdot f$

According to test results, we calculate that the use of engine brake (Jacobs), the braking force of each block with the speed of the curve in Figure 1.

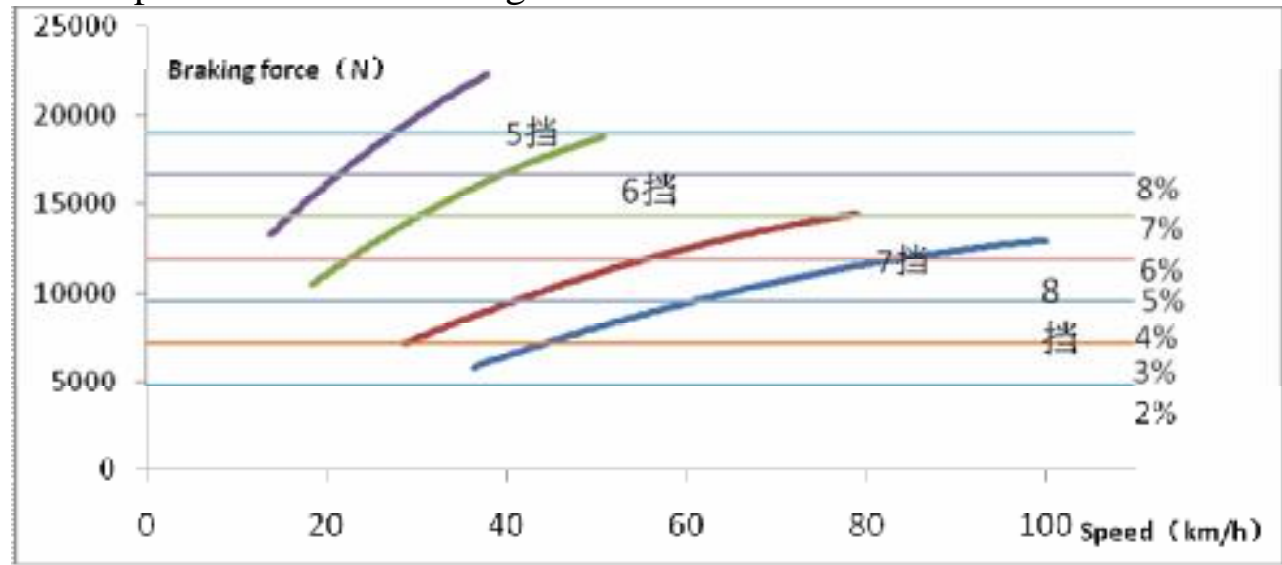

Figure 1 the total braking force curve that each block of engine brake with the speed change

\section{Engine brake (Jacobs) braking power measurement and calculation}

According to engine power formula:

$P_{\mathrm{e}}=T_{\mathrm{tq}} \omega_{\mathrm{e}}=\frac{T_{\mathrm{tq}} i_{\mathrm{g}} i_{0}}{r} u$

We can calculate the braking power of the engine, as shown in Table 2 and Figure 2.

Table 2 ISM345 30 engine brake (Jacobs) braking power and driving power

\begin{tabular}{|c|c|c|c|c|c|c|}
\hline $\begin{array}{c}\text { Engine speed } \\
(\mathrm{r} / \mathrm{min})\end{array}$ & 1000 & 1200 & 1400 & 1600 & 1800 & 1900 \\
\hline $\begin{array}{c}\text { Braking } \\
\text { power(KW) }\end{array}$ & 52 & 73 & 96 & 121 & 147 & 160 \\
\hline $\begin{array}{c}\text { Driving } \\
\text { power(KW) }\end{array}$ & 159 & 214 & 230 & 244 & 251 & 254 \\
\hline $\begin{array}{c}\text { Braking power/ } \\
\text { Driving power }\end{array}$ & $32.7 \%$ & $34.1 \%$ & $41.7 \%$ & $49.6 \%$ & $58.6 \%$ & $63.0 \%$ \\
\hline
\end{tabular}

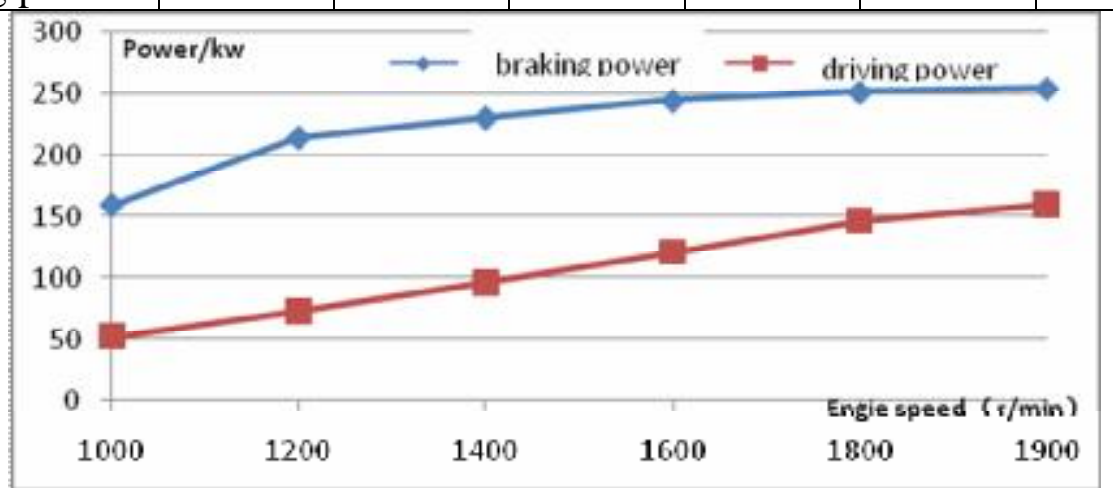

Figure 2 Engine brake (Jacobs) power characteristic curve (ISM345 30)

The calculated results show that, at the rated speed $1900 \mathrm{r} / \mathrm{min}$, the engine driving power is $254 \mathrm{KW}$; the braking power is equivalent to $63.0 \%$ of the driving power. At the Maximum speed of $2300 \mathrm{r} / \mathrm{min}$, the braking power is $211 \mathrm{~kW}$, equivalent to $83.1 \%$ of the rated driving power.

\section{The Yaxi mountain highway long downhill safety tests}


In order to test the safety degree of medium truck which install the engine brake (Jacobs), driving through a mountain highway longitudinal sections, we choose North Niba mountain slope $(25.6 \mathrm{~km})$, and North Tuowu mountain slope $(51 \mathrm{~km})$ on Yaxisi highway to conduct field tests.

The test truck total weight of the total weight of 32.5 tons (overload $30 \%$ ) when going downhill, turn off the water spray device, turn on or off the engine brake system to carry comparison tests of the two conditions, if necessary, using the service brake to control speed.

Safety tests on the Niba mountain north slope $(26 \mathrm{~km})$

(1) Turn off the water spray device and engine brake(Jacobs)when driving downhill

During entire process of driving, the truck's transmission on 7-8 file (high), ambient temperature (NA), the right front brake drum temperature (RF), right after the front axle brake drum (RR1), speed and other parameters as shown in Figure 2 below.

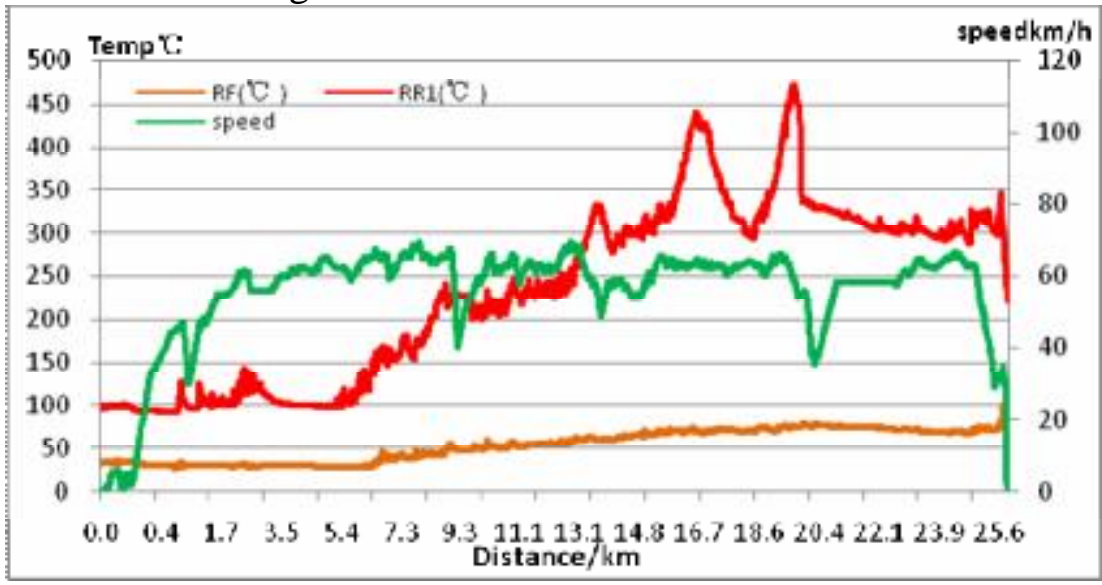

Figure 3 Truck overloaded 30\% driving downhill, turn off the water spray and engine brake system, brake drum Temp, speed change curve, north Niba mountain slope

The figure 3 shows that, the entire process takes 27 minutes 46 seconds, max speed is $69.7 \mathrm{~km} / \mathrm{h}$, average speed is $55.6 \mathrm{~km} / \mathrm{h}$, Braking time the proportion of the total travel time of $69.2 \%$; because the front axle load is light, so the right front wheel brake drum temperature change is small, the max temperature is $100^{\circ} \mathrm{C}$. The rear axle load is larger, thus the temperature rise is faster, the max temperature of the right front axle wheel brake drum up to $472.7^{\circ} \mathrm{C}$.

According to the conclusions of the western project of the Ministry of Transportation, when the brake drum temperature reaches $260^{\circ} \mathrm{C}$, the vehicle will lose emergency braking ability. Therefore, in the long downhill sections of mountain highway, for the heavy load trucks, if the brake drum is not watering, and no auxiliary braking device under the conditions, the brake performance is easy to reduce to the limit due to brake drum overheating, resulting in the vehicle lost control and traffic accidents.

(2)Turn off water spray device and turn on engine brake(Jacobs)when driving downhill

The second test same with the first trial, downhill gear and the same working conditions, turn on the engine brake (Jacobs), when going downhill, the truck's parameters as shown in figure 4.

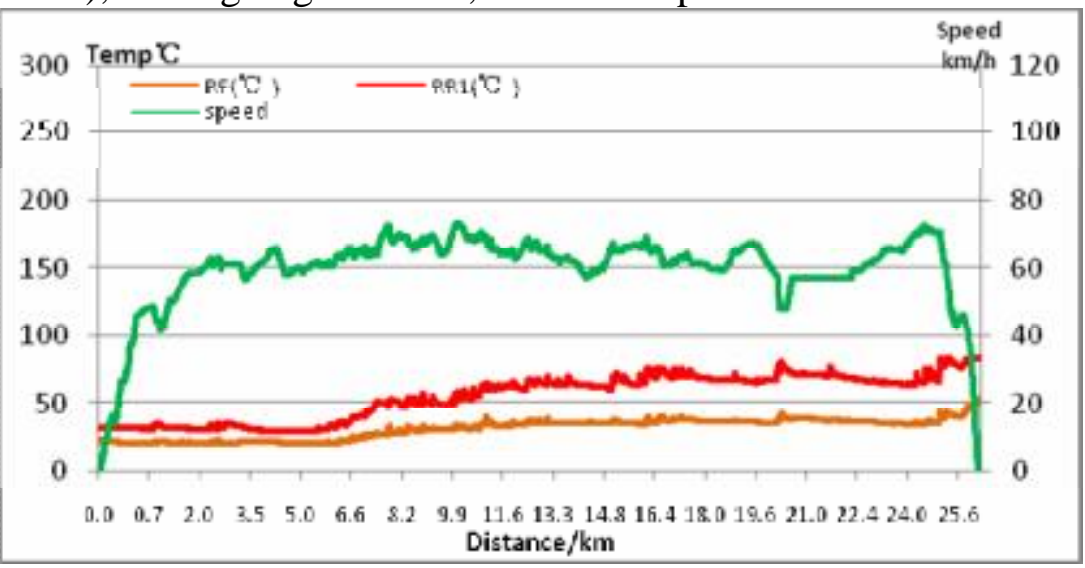

Figure4 Truck overloaded 30\% driving downhill; turn on the water spray and engine brake system, brake drum Temp, speed change curve, north Niba mountain slope 
From figure 4 we can see that, the entire downhill process takes 26 minutes 14 seconds, maximum speed is $59.4 \mathrm{~km} / \mathrm{h}$, average speed is $55.6 \mathrm{~km} / \mathrm{h}$, Braking time the proportion of the total travel time of $47.1 \%$; because the act of engine brake (Jacobs), The use of the frequency and intensity of the brake are greatly reduced, so the brake drum temperature rise is slow, the right front wheel brake drum temperature change is small, the range is less than $50^{\circ} \mathrm{C}$. The maximum temperature of right front axle brake drum reached $149.7^{\circ} \mathrm{C}$.

Thus, under the conditions of the engine brake (Jacobs), medium truck even if overload 30\% when going long downhill slope, still can ensure the effectiveness of the braking system so that the truck can run down a long slope to faster security.

\section{Safety tests on the Tuowu mountain north slope $(51 \mathrm{~km})$}

In order to further test the reliability of medium truck engine brake (Jacobs) on long downhill slope section, the research group carried the $51 \mathrm{~km}$ long downhill slope test on Tuowu mountain north slope on Yaxi highway, the truck is still overloaded 30\% load when going downhill, turn off the water spray device, open the engine brake (Jacobs), try not to use the service brake, the test results as shown below:

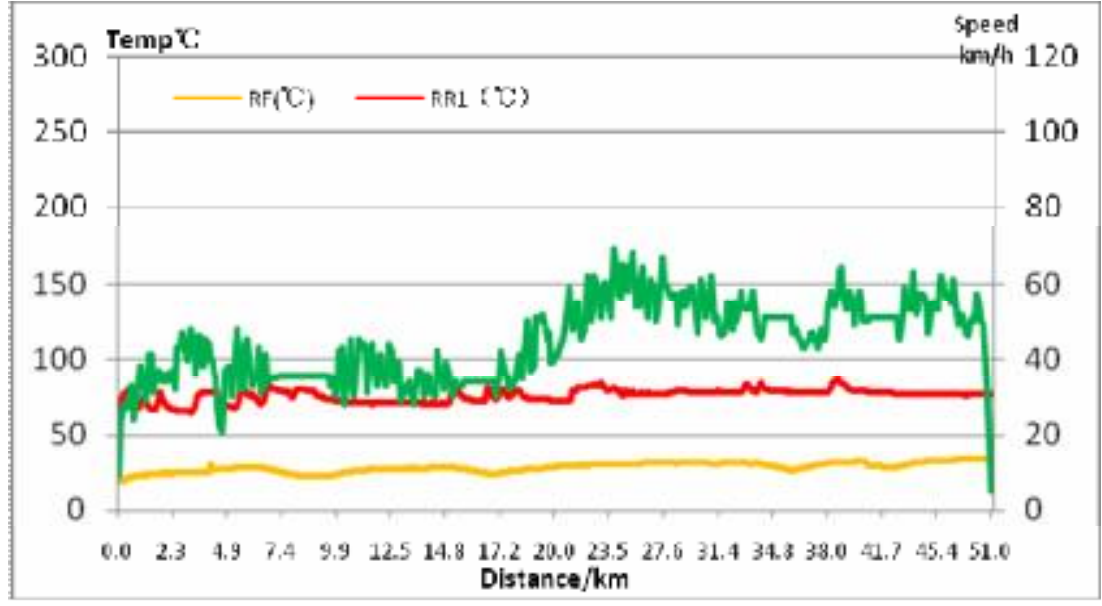

Figure 4 Truck overloaded 30\% driving downhill; turn on the water spray and engine brake system, brake drum Temp, speed change curve, north Tuowu mountain slope

\section{Summary}

(1) At the loading of no more than standard level, only under the traction of engine braking (Jacobs), the medium truck can pass through the long downhill sections of mountain highway without spraying water to cool brake drum, and the speed is more appropriate in the $60 \mathrm{~km}$ or so.

(2) When $30 \%$ overloaded, the medium truck can also pass through the long downhill sections of mountain highway only under the use of engine braking (Jacobs), and the speed control is more appropriate in the $50 \mathrm{~km}$ or so.

(3) Due to there are many engine braking system manufacturers in China, so the product quality is also difference, therefore, suggested that when the medium truck going long downhill sections of mountain highway, it's necessary for it to store enough water in the tank, so as to prepare for contingencies.

Engine auxiliary braking technology has been widely used in the United States and Europe, which has become the standard configuration of the commercial vehicles, and greatly improved the safety of commercial vehicles when pass through mountain highway long downhill. However, because of truck engine power is low relative in Europe and America, and the braking power is closely related to driving power of the engine, therefore, it can only ensure the medium truck pass through long downhill slopes safety. For large semi-trailer vehicles, the retarder brake assist system should be installed to ensure driving safety. 


\section{References}

[1] CHEN Yinsan, YU Qiang, MA Jian. Experiment research on supplementary brake [J]. Journal of Xi' an Highway University, 2000, 20 (2) : 69-70. (in Chinese).

[2] YU Qiang, CHEN Yin2san, MA Jian. Function analysis on exhaust brake of bus [J]. Journal of Xi'an Highway University, 2000, $20\left(\mathrm{~S}_{0}\right): 95-97$. ( in Chinese)

[3] YU Qiang, Study on downhill continuous braking performance of automobile [D]. Chang'an University, 2000

[4] WU Guang-qiang. Autotheory [M]. Beijing; China Communications Press, 2007.

[5] WEI Lang, CHEN Tao. A simulation study on the vehicle speed control mode of drivers [J]. Automotive Engineering, 2005,27(6):696-701. 